\title{
Posterior Interosseous Nerve Palsy Caused by a Ganglion
}

\author{
Akira Yokote ${ }^{1}$, Shinsuke Fujioka ${ }^{1}$, Toshiyuki Ishiko ${ }^{2}$ and Yoshio Tsuboi ${ }^{1}$
}

Key words: radial nerve, posterior interosseous nerve palsy, ganglion, drop finger

(Intern Med 58: 1661-1662, 2019)

(DOI: 10.2169/internalmedicine.1610-18)
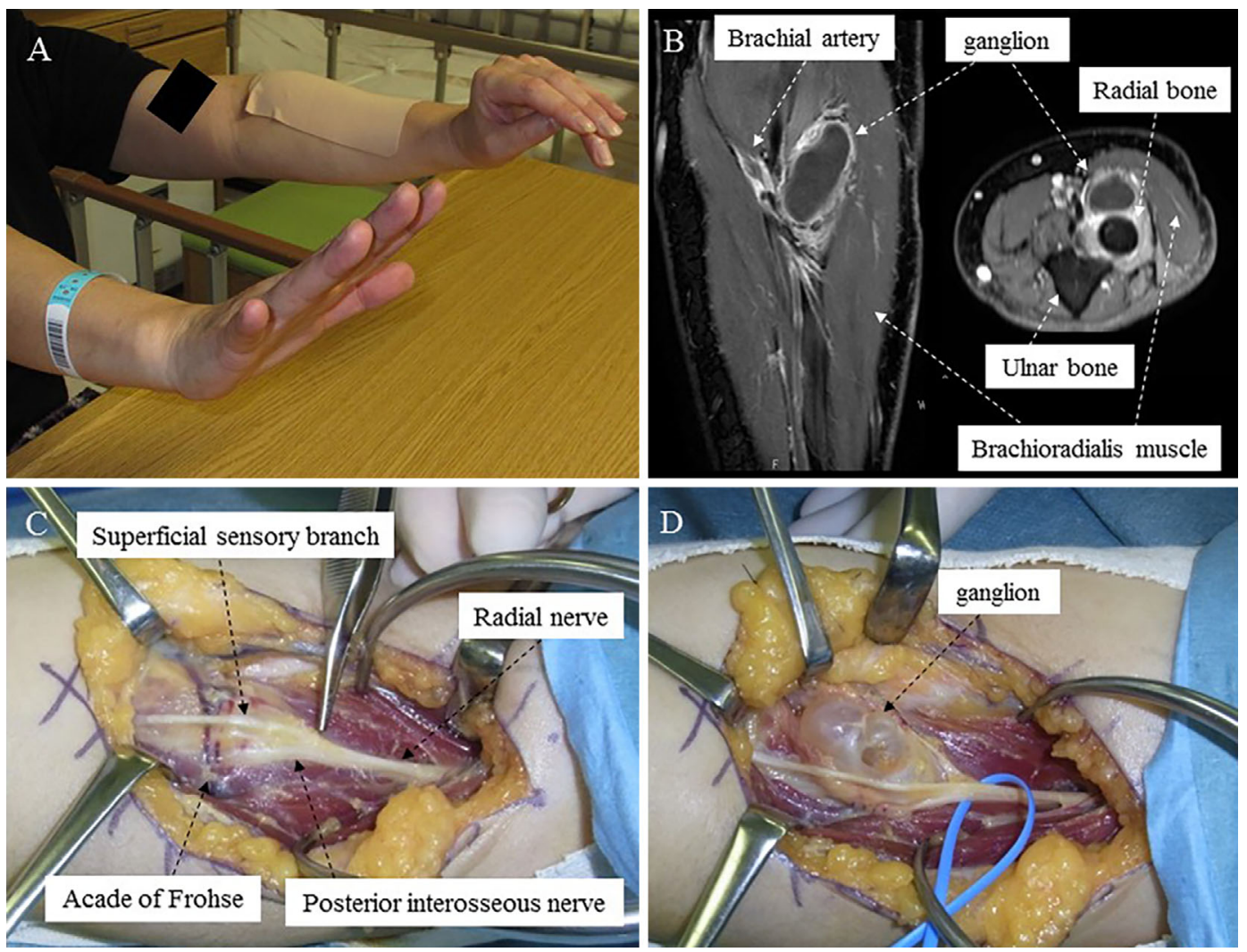

Picture.

A 46-year-old woman complained of difficulty extending her left fingers for 1 month prior to visiting our hospital. A neurological examination revealed weakness of the left abductor pollicis longus, extensor pollicis brevis, extensor digitorum and extensor carpi ulnaris muscles. Finger drop was observed (Picture A). Sensory disturbance was not seen. A painless soft mass was also identified in the left proximal forearm. Gadolinium-enhanced fat-suppressed T1-weighted MRI of the left forearm showed a cystic mass lesion and contrast-enhanced capsule at the radio-ulnar joint in the el- bow (Picture B). Nerve conduction studies showed the reduced amplitude of the compound motor action potential in the extensor indicis muscle of the left radial nerve. The tumor was surgically removed (Picture C, D). A histological examination revealed that the tumor was a ganglion. At six months after the surgical removal of the tumor, the patient's symptoms had completely resolved. We emphasize the importance of investigating the possibility of a ganglion as a treatable cause of mononeuropathy (1).

${ }^{1}$ Department of Neurology, Fukuoka University School of Medicine, Japan and ${ }^{2}$ Department of Orthopaedic Surgery, Fukuoka University School of Medicine, Japan

Received: May 30, 2018; Accepted: November 25, 2018; Advance Publication by J-STAGE: February 1, 2019

Correspondence to Dr. Yoshio Tsuboi, tsuboi@ cis.fukuoka-u.ac.jp 
The authors state that they have no Conflict of Interest (COI).

\section{Reference}

1. Tuygun $\mathrm{H}$, Kose $\mathrm{O}$, Gorgec M. Partial paralysis of the posterior interosseous nerve caused by a ganglion. J Hand Surg Eur 33:
540-541, 2008.

The Internal Medicine is an Open Access journal distributed under the Creative Commons Attribution-NonCommercial-NoDerivatives 4.0 International License. To view the details of this license, please visit (https://creativecommons.org/licenses/ by-nc-nd/4.0/).

(C) 2019 The Japanese Society of Internal Medicine Intern Med 58: 1661-1662, 2019 